Received:13.05.2021

doi: 10.46763/JESPT211610055u

Udc:81'243:37.091.279.7

Revised: 21.05.2021.

Accepted: 29.05 .2021

\title{
SEMANTIC FEATURES OF KINSHIP TERMS IN MACEDONIAN, ENGLISH AND GERMAN
}

\section{Tatjana Ulanska', Dragana Kuzmanovska², Snezana Kirova ${ }^{3}$, Biljana Ivanova ${ }^{4}$}

\author{
'Faculty of Philology, Goce Delchev University, Shtip, Macedonia \\ tatjana.ulanska@ugd.edu.mk \\ ${ }^{2}$ Faculty of Philology, Goce Delchev University, Shtip, Macedonia \\ dragana.kuzmanovska@ugd.edu.mk \\ ${ }^{3}$ Faculty of Philology, Goce Delchev University, Shtip, Macedonia \\ snezana.kirova@ugd.edu.mk \\ ${ }^{4}$ Faculty of Philology, Goce Delchev University, Shtip, Macedonia \\ biljana.petkovska@ugd.edu.mk
}

\begin{abstract}
Abstract. This paper describes the semantic features of kinship terms in Macedonian, English and German and attempts to make a complete analysis in these languages. The paper compares the semantics of kinship terms from a perspective of a comparative analysis of Macedonian, on one hand with English and German on the other, as they belong to different language groups. These terms have proven to have specific particularities which differ in system structure. The comparison between these three languages will show both similarities and differences in the lexical fields of kinship terms, especially in Macedonian to English and German. Kinship terms have been a subject of interest from various perspectives and analyses since these terms show unique national features. Additionally, they have been discussed and researched from a cultural aspect as well, since they seem to convey information about the cultural life of the people who speak a certain language. Therefore, kinship terms can also be seen as a social symbol. The paper provides an insight into the comparative analysis presenting similarities and differences in the lexical fields of kinship terms and, finally, draws a few conclusions and insights concerning their cultural peculiarities.
\end{abstract}

Keywords: Macedonian language, English language, German language, kinship terms, semantic features.

\section{Introduction:}

The notion of kinship has been widely addressed by anthropologists, linguists, evolution biologists and mainly by social anthropologists. The introduction of kinship terms dates to ancient times to serve as terms to express biological and genetic relatedness and genetic inheritance. Kinship terms based on family, family relations and marital relations are semantic categories originating to the very first lexical items forming a lexical field that make reference of a person based on kinship relation. Being the terminology that originates from ancient times, it is inevitable that this lexical and semantic system has undergone a number of changes. These changes have included also word-formation processes of derivation, in particular in the Macedonian language. The first serious attempt to make organization and classification of these terms was by the anthropologist Henry Morgan. As explained so far, the need to organize this terminology has been an inevitable requirement in any language systems. All societies today have terms to refer or address different persons who do not necessarily need to be in blood relation to. This terminology has proven to be the mirror of the mentality of the people of one society and in great deal reflect the way relationships are perceived. Consequently, there is vast difference in the terminological systems and the standard taxonomy of kinship terms. Discussing the topic of kinship directly takes us to the first serious and significant categorization, which was published in 1870 and written by Lewis Henry Morgan, named 'Systems of Consanguinity and Affinity of the Human Family' (Morgan, 1870). With a significant amount of data on kinship terminology he created the first classification of kinship systems. Morgan was actually the one who separated the terms of 
kinship from the vocabulary and created a field and grouped them in a set. He claimed that societies and humans evolve and have progressed from primitive savagery to civilization, and he also insisted that these kinship terminologies are reflecting these changes and evolutions. His research finalized in differentiating between two kinship terms - classificatory and descriptive. The societies that have these classificatory systems are more common and present in many more languages than the ones described as 'descriptive' kinship terminological systems. The characteristics of these systems are that they express relationships of blood separately than those of collateral line.

The various types of mappings of the kinship terminology that exist serve to witness the various focus it had been added over the years, i.e. differentiating among and grouping them in separate lexical subfields based on various differences. After Morgan, other anthropologists followed to finally contribute to a nomenclature that is widely accepted and was the foundation of several categorizations of kinship terms. The view and aspect that is of our interest is the categorization of the six major terminological systems. Those are: Hawaiian, Iroquois, Omaha, Crow, Sudanese and Eskimo.

\section{Kinship terms in Macedonian, English and German}

Different cultures and societies represent kinship varying from very limited to wide range of terms. Kinship terms in these diverse varieties of language systems are most evident in the respective kinship terms of reference. The varieties of these terms are mainly grouped as primary, secondary and tertiary. The primary kinship terms are related to ego directly, and then secondary kin is the kin related to ego through the primary kin, and, finally tertiary kin is the person who is related to ego through a secondary kin. In the more elaborate systems, there are also kinship terms used for referring to and addressing a particular person of relation. The term of reference is the lexeme used to describe. i.e. provide information about the relationship, while there are also these terms for addressing that are present in some systems and used to address a particular person of family relation. In the Macedonian language, as opposed to English and German, there is a significant number of these terms of address. On the other hand, the English and German lexical fields of kinship terminology have terms that represent merging two, three or more kinship terms which share similarities of relation or status, under one name (grandparents, siblings, etc.) (Trautmann, T.R. 1981). This is not a characteristic of the Macedonian language.

For the purpose of comparison of the kinship terms among these three languages we will briefly discuss Kroeber's views and work done in this field (Kroeber, 1936). He debated the basic typology done by Morgan regarding the kinship terminology. According to Kroeber the distinction between classificatory and descriptive systems is not thorough since all systems include both, and additionally pointing the need to have a frame of reference that will exclude the need to make direct translations. Nevertheless, the main differences of the terminological systems to which these three languages belong to will be presented here.

The typology of the Macedonian language, according to its features falls into the Sudanese terminological system. This kinship typological system is descriptive and probably considered the most complex one. Its complexity is due to the fact that for every relation to Ego, there seem to be a separate term for each relation, marking the difference based on relationship, side (mother's or father's) and gender. The majority of the Slavic languages, in great part follow the typology of the Sudanese type due to the large number of kinship terms and the diversity as mentioned above. For example, the relationship of a cousin can reach to eight different terms in some Slavic languages. A characteristic and a feature different from the English and German language is that Macedonian has terms for all relatives of Ego differentiating mother's or father's side and gender. The Macedonian language, as it is the case with most of the Slavic languages, does not fully represent the Sudanese system and its categorization, but it is the one that is the closest. An illustration of this descriptive system which most closely describes the Macedonian terminology of kinship would be the terms for the relationship of Ego to mother's brother and father's brother and the mother's or father's sister's husband. The terms in Macedonian respectively would be вујко, чичо/ стрико and тетин. In other terms, Macedonian system of kinship classifies kinship relations by distinguishing between consanguine (blood relation) and affinal (relationship created between two people as a result of someone's marriage) aunts and uncles. Also, the terms of address to the first two relatives are similar, but still different. The ones being вујче аnd чичко 
respectively. An additional illustration of the descriptiveness of this typology are the different terms for niece and nephew in Macedonian, differentiating based on the gender of the relative to Ego, and there are the terms братанец, братаница the niece and nephew from Ego's brother and сестричник и сестричница from Ego's mother. However, in the more contemporary Macedonian, there seems to be a tendency to break free from this tradition and collapse these terms into one, being niece and nephew.

The descriptiveness of the typology of the Macedonian system of kinship appears to be opposite of the systems in English and German. Namely, the typology of German and English kinship is linear and does not make any difference between the relatives from mother's or father's side i.e., the terminology is the same. These two languages belong to Morgan's Eskimo typology. This typology focuses on differences in kinship distance i.e., the closer the relative is, the more distinctions are made. The focus of this typology is on the nuclear family. All other relatives are grouped together into categories and no distinctions are made between patrilineal and matrilineal relatives. This system is classificatory, but it also has descriptive terms, differentiating between gender, generation, lineal relatives and collateral relatives. Parental siblings are distinguished only by their sex and we have the terms aunt and uncle in English, as it is in German, whereas the differentiation of the children of parental siblings, these languages have only one term, regardless of sex i.e., cousin. In Macedonian the gender is marked and there are братучед (male cousin) and братучетка (female cousin).

The English kinship terminology is almost completely the same with the German, with several exceptions in terminology. Namely, we can mention the terms used in German that correspond to the English brother-in-law and sister-in-law. The German terminology includes both der Schwager и Schwippschwager (spouse's sister's husband) and for sister-in-law German terminology has die Schwägerin и Schwippschwägerin (spouse's brother's wife). In German, a Schwippschwager is a distant brother-in-law or sister-in-law i.e., a sibling or spouse of those who have married into the family. The prefix Schwipp-is considered to be an abbreviation of the word Geschwister, meaning siblings. There is no term to mark this relationship in English, even though they belong to the same typology. However, here we can make the comparison with Macedonian. In Macedonian there are the terms сват and сваќa to refer to the male and female distant relatives respectively, that have married into the family. The existence of such term in German serves to prove that there is no complete or strict belonging of any language to a certain typology. In addition, Macedonian does not normally have collective terms to refer to both male and female relatives, like in English and German, such as siblings or grandparents so in Macedonian they are simply conjoined with conjunction i.e. брат и сестра or баба и дедо. Nevertheless, for the affinal relatives, there is a collective term in Macedonian сватови. This is another example that languages belong to a certain typology only in general. There are exceptions to the rules at least in these three languages. This data gives us a window where we can acknowledge and differentiate social features, behavioral patterns, closeness and relations with terminological patterns. And, finally, the mentality and the social relationships in a society are quite well illustrated with kinship terms. For instance, in Macedonian the parents of close friends are addressed with uncle and aunt i.e., чичо and тетка. This illustrates the mentality and the social relationship of the Macedonian culture, using this terminology to illustrate closeness even when there is no family connection. Whereas, in English and German, the parents of close friends are addressed with Mr. or Mrs. and the last name.

\section{Conclusion:}

Discussing kinship terminology from a social point of view and linguistically includes thoughts about ways to describe relationships and its terminology as well as behavior within the society. Macedonian kinship is in the Sudanese typology, same as Turkish. The connection and similarities in the Macedonian typology might have been influenced to some degree from the long and constant Ottoman influence in duration of five centuries in the Balkans. The purpose of the number of examples included in the main body of this paper were not only to present the similarities and differences in the lexical fields of kinship terms, especially in Macedonian to English and German, but also to illustrate the overlap in certain terms and features despite the distance of language families, kinship typology and, mentality, culture and behaviors. Kinship terms have been a subject of interest from various perspectives and analyses since these terms show unique national features. Additionally, they have been discussed 
and researched from a cultural aspect as well, since they seem to convey information about the cultural life of the people who speak a certain language. Therefore, kinship terms can also be seen as a social symbol. This paper's aim is to evoke interest and thoughts regarding the peculiarities, special features, historical influences, cultural differences and the influence of mentality to the formation of this lexical field in the three languages. In this context, the linguistic relativity of Whorf-Sapir's work is quite relevant in this context. Their theory raises the question of how much language influenced thought, and in what ways. The relativity question in interested in the linguistic coding of categories and relationships and the ways in which that influences people's thoughts and views, especially collective views, due to the fact that this theory rests upon the great influence of the language on the its speakers.

\section{References}

E. Stoevska-Denčova, (2009). „Imenuvanje na rodninskite odnosi vo makedonskite dijalekti od slovenski I balkanistički aspekt ", Institut za makedonski jazik "Krste Misirkov", Skopje [Naming of kinship relations in the Macedonian dialects from the Slavic and Balkanist aspect] Institute for Macedonian Language "Krste Misirkov", Skopje.

Stefanovski, Lj, (2007). English Lexicology - coursebook

Nikolovska, V., (2013). Što izgubivme niz vremeto (na primeri od jazikot) "Jazikot naš denešen" Zbornik na trudovi od XVII naučen sobir, Institiut za makedonski jazik "Krstte Misirkov", Skopje [What we have lost over time (on language examples). "Our Language Today" Proceedings of the XVII Scientific Meeting], Institute for Macedonian Language "Krste Misirkov" - Skopje

Petreska, V., (2005). Sistem na srodstvo kaj Makedoncite, Institut za folklor "Marko Cepenkov" Skopje, Posebni Izdanija, kn. 59, Skopje. [System of kinship among the Macedonians], Institute of Folklore "Marko Cepenkov" -Skopje, Special editions, book 59, Skopje.

Jones, D. (2010). Human kinship, from conceptual structure to grammar. Behavioral and Brain Sciences

Kemp, C. \& Regier, T. (2012). Kinship categories across languages reflect general communicative principles. Science https://doi.org/10.1126/science.1218811

Kroeber, A., (1936) Kinship and History. American Anthropologist

Morgan, Lewis Henry (1870) Systems of Consanguinity and Affinity of the Human Family. Smithsonian Contributions to Knowledge, vol. 17. Washington, DC: Smithsonian Institution.

Stone, L. (2000) Kinship and gender: An introduction. Westview.

Strier, K. B. (2004) Patrilineal kinship and primate behavior. In: Kinship and behavior in primates, ed. B. Chapais \& C. M. Berman. Oxford University Press.

Trautmann, Thomas R. (1981) Dravidian Kinship. (Cambridge Studies in Social Anthropology, vol. 36.) Cambridge: Cambridge University Press. https://doi.org/10.1017/s0041977x00079234

Trautmann, T. R. (1987) Lewis Henry Morgan and the invention of kinship. University of California.

Trautmann, T. R. \& Barnes, R. H. (1998) "Dravidian," "Iroquois," and "Crow-Omaha" in North American perspective. In: Transformations of kinship, ed. M. Godelier, T. R. Trautmann \& F. E. Tjon Sie Fat. Smithsonian Institution Press.

Wierzbicka A. (1992). Semantics, culture, and cognition. New York: Oxford University Press 